\title{
The ECLIPSE drill: a field-portable intermediate-depth ice-coring drill
}

\author{
Erik W. Blake, ${ }^{1}$ Cameron P. Wake, ${ }^{2}$ Michael D. Gerasimoff ${ }^{1}$ \\ ${ }^{1}$ Icefield Instruments Inc., PO Box 5567, Whitehorse, Fukon Y1A 5H4, Canada \\ ${ }^{2}$ Climate Change Research Center, Institute of the Study of the Earth, Oceans and Space, \\ University of New Hampshire, Durham, New Hampshire 03824, U.S.A.
}

\begin{abstract}
A derivative of the Danish tipping-tower intermediate-depth ice-coring drill system has been developed for use in remote areas. The system as described is capable of drilling to depths of $250 \mathrm{~m}$, although the drill has been proven to $350 \mathrm{~m}$. The drill system is designed to be transported by hand and consumes $700 \mathrm{~W}$ maximum power from a $24 \mathrm{~V}$ d.c. battery bank charged by solar panels or a small generator. A field test in the St Elias Mountains, Yukon, produced good-quality core to $161.6 \mathrm{~m}$ depth; drilling at $6500 \mathrm{~m}$ a.s.l. on Far East Rongbuk Glacier, Mount Everest, produced good core to $42 \mathrm{~m}$ depth.
\end{abstract}

\section{INTRODUGTION}

The University of Copenhagen tipping-tower intermediatedepth electromechanical ice-coring drill system and its predecessors were developed in the 1970s (Rand, 1976; Rufli and others, 1976; Johnsen and others, 1980; Gundestrup and others, 1989). In 1992, the Geological Survey of Canada (GSC) tested their version of this drill system (called "HILDA") on Agassiz Ice Cap, Ellesmere Island, Northwest Territories. In subsequent years, drilling on Agassiz Ice Cap (1993, 1994) and Penny Ice Cap, Baffin Island (1995, 1996), proved that HILDA can drill dry holes to $350 \mathrm{~m}$, while producing good-quality ice core. HILDA produces $82 \mathrm{~mm}$ diameter core in roughly $90 \mathrm{~cm}$ lengths with virtually complete core recovery (personal communication from D. Fisher, GSC).

In 1995, the authors began work on a lightweight, handportable version of HILDA designed for high-altitude work in the Himalaya. The requirements for the new drill system were that: (1) the complete system should mass no greater than $200 \mathrm{~kg}$; (2) no component should mass greater than $32 \mathrm{~kg}$; (3) the system should produce good core in a dry hole to $200 \mathrm{~m}$ depth; and (4) it should be able to operate from a $1000 \mathrm{~W}$ solar-panel array.

The resulting design, named "ECLIPSE" after the test site at Eclipse Dome, St Elias Range, Yukon, was field-tested in late-July 1996 and field-proven on Mount Everest in May 1997.

\section{WINCH DESIGN}

In meeting the design requirements, using HILDA as a design reference, it was decided that the major mass savings should ensue from redesigning the winch and tower rather than the drill; this was because the HILDA drill is now a proven technology.

As sketched in Figure 1, the frame consists of an open triangular base supporting a square face-frame. The face- frame, in turn, supports two upright L brackets that hold the winch tower. The face-frame is held upright by two diagonal braces that also support the winch drum, hand winch and winch motor. A final upright near the apex of the base members forms a support for the tipping tower when in the horizontal position. All frame members are 2 in $(5.08 \mathrm{~cm})$ square extruded 6061-T6 aluminium tubing. This frame design results in a lightweight, easily assembled yet rigid winch. The winch masses $120 \mathrm{~kg}$ with $250 \mathrm{~m}$ of cable.

The winch motor is a custom-built $3000 \mathrm{rpm}, 24 \mathrm{~V}$ d.c. motor drawing $40 \mathrm{~A}$ at full load; it is equipped with an electric brake and tachometer. The output from the motor is reduced through an 80:1 Harmonic Drive transmission. The winch drum is chain-driven at a $1: 1$ ratio from the transmission output and is equipped with a disc brake. A hand crank drives the drum at a $4: 1$ ratio.

Figure 2 shows the hinge action of the ECLIPSE drill

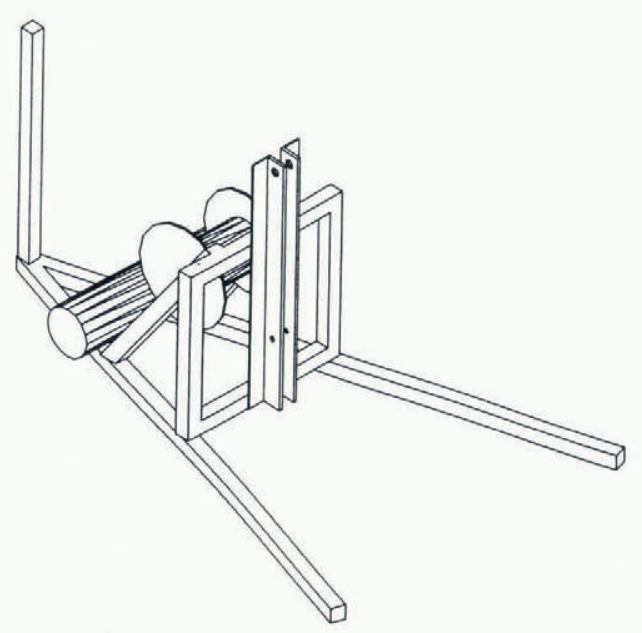

Fig. 1. A perspective view of the lightweight cross-braced winch. The hand crank (not shown), winch drum and winch motor are mounted on the two diagonal braces. The hinged tower (not shown) is mounted at the top of the two L sections. 


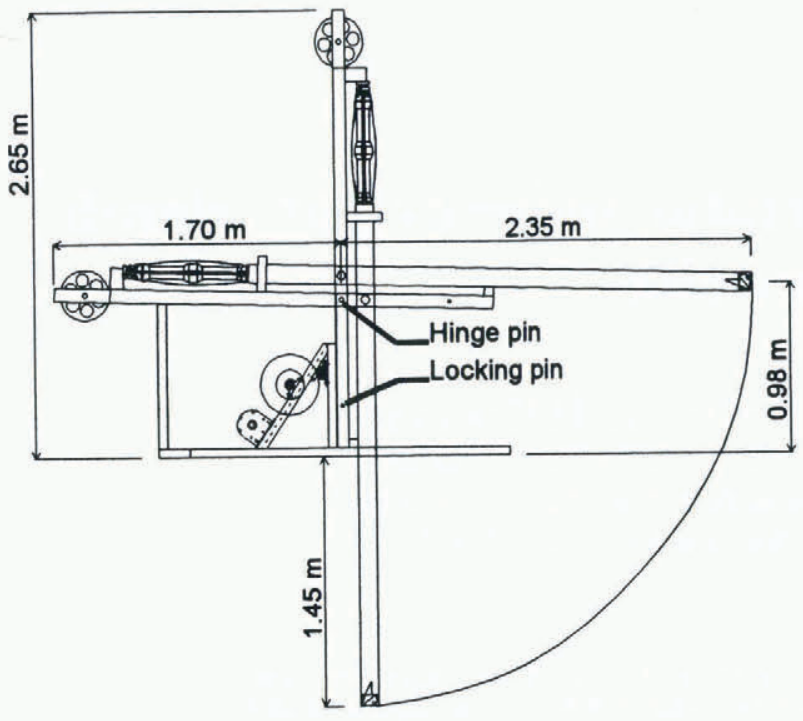

Fig. 2. A side view of the drill, showing the tower and drill in both horizontal and vertical (drilling) positions. The antitorque section of the drill is visible at the top. In the horizontal position, a slight downward angle is maintained to facilitate removal of the inner barrel.

winch/tower with the drill held in its cradles. Clearances around the drill are noted on the drawing. A $1.5 \mathrm{~m}$ deep trench is required to accommodate the drill when in the vertical position. We also install a trapdoor at the bottom of the trench; the door prevents foreign objects from falling into the hole whenever the drill is at the surface. In its horizontal position, the drill has a slight $\left(1.5^{\circ}\right)$ downward angle to assist in removing the inner barrel. An optical encoder attached to the tower sheave measures cable travel.

\section{DRILL GABLE}

The authors decided to use steel cable rather than Kevlar cable, as the former is more compact and rugged. Steel cable can also accept a smaller bending radius, thereby permitting a smaller, lighter drum and sheave. The cable used for the drill is Vector Schlumberger 4-18P armoured steel welllogging cable, having a diameter of $4.8 \mathrm{~mm}$, a breaking strength of $14 \mathrm{kN}$ and a mass of $91 \mathrm{~kg} \mathrm{~km}^{-1}$.

The cable has four 24 AWG copper conductors, each with an electrical resistance of $85 \Omega \mathrm{km}^{-1}$. The sheath has a resistance of $22 \Omega \mathrm{km}^{-1}$. Two of the conductors are paired to supply power to the motor (with ground return through the cable sheath); the remaining conductors are used for the tachometer. An anti-torque failure alarm was not included in this ECLIPSE design but could be implemented with a slight modification of the tachometer circuit. The drill advances reliably once drilling has begun; cessation of advance normally occurs only when the drill motor stalls due to overfilling, a condition that can be distinguished from anti-torque failure by examining the tachometer reading.

\section{DRILL}

The ECLIPSE drill has an overall length of $3.6 \mathrm{~m}$ and a mass of $50 \mathrm{~kg}$. The drill has three major components: a motor/antitorque section, a rotating inner barrel and a non-rotating outer barrel.

The inner barrel is a $231 \mathrm{~cm}$ long, $3.50 \mathrm{in}(89 \mathrm{~mm})$ out- side-diameter thin-wall stainless-steel tube fitted with three nylon spirals. Each spiral has a pitch of 7.0 in $(178 \mathrm{~mm})$. An aluminium cutter head equipped with three hardened toolsteel cutters is attached to the inner barrel. The cutter head follows closely the design of Gundestrup and others (1989). The cutters are equipped with a selection of trailing shoes that set the maximum cut depth (shoes 3-6 have a nominal $3,4,5$ or $6 \mathrm{~mm}$ of cut per revolution, respectively). The cutters have a cutting angle of $45^{\circ}$, a relief (or free) angle of $15^{\circ}$ and a rake angle of $7^{\circ}$ (leading edge on the inside). There is no relief angle on the sides of the cutter. The cutter head also has three core dogs which serve to break and hold the core. The inner barrel is attached to the drive capstan of the motor section with three bayonet-type locking pins inserted through an access port in the outer barrel.

The fixed (non-rotating) outer barrel has an outside diameter of 4.25 in $(108 \mathrm{~mm})$ and has 30 straight grooves cut into its inner surface. These grooves extend from the bottom end of the barrel to the access port and serve to assist chip transport. The radial clearance between the inner and outer barrels is approximately $0.6 \mathrm{~mm}$.

The motor section contains a custom $3750 \mathrm{rpm}$, $200 \mathrm{~V}$ d.c. motor, a tachometer and a 50:1 Harmonic Drive gear reducer in a sealed housing. The anti-torque section uses three leaf springs to provide pressure against the borehole walls (Reeh, 1984). The wall pressure is adjustable using two locking nuts. The anti-torque section also contains a hammer mass and a slip-ring assembly (Litton Poly-Scientific AC4898 series).

The inner barrel and cutter head are driven at $75 \mathrm{rpm}$ by the drill motor. Chips are carried up the flights and dumped into the inner barrel through chip ports located at the top of the spiral flights. The chips fall on to a nylon core-separator plug that rests on top of the ice core. Core is removed at the surface by tipping the winch tower to a horizontal position, removing the three locking pins and extracting the inner barrel from the drill. The separator plug serves two purposes: (1) it helps keep the chips clear of the core, and (2) it allows the chips to be carried out of the hole should no core be recovered.

\section{CONTROL MODULE}

The control module takes a nominal $24 \mathrm{~V}$ d.c. input from a lead-acid battery bank; the input to the module is polarityprotected. A MOSFET pulse-width modulator (PWM) circuit provides power for the winch motor (current limit is 50 A). A 40-250 V d.c. switcher-type circuit provides power for the drill motor (current limit is $2 \mathrm{~A}$ ). Control functions provided include: (1) drill-motor start, stop, direction and speed; (2) winch-motor start, stop, direction and speed; (3) winch emergency-stop switches on the winch frame; (4) tower stop switch to stop winch motor when the drill has been raised; and (5) lockout functions for preventing motor starts when motors are turning. Display functions provided include: (1) drill-motor current and speed; (2) winch-motor current and speed; (3) battery voltage and current draw; and (4) drill depth.

The control function, display functions and PWM circuitry are implemented on a single $75 \mathrm{~mm}$ by $250 \mathrm{~mm}$ circuit board; the commercial switcher-type supply for the drill motor is in a separate $15 \mathrm{~cm}$ by $15 \mathrm{~cm}$ by $35 \mathrm{~cm}$ enclosure. Relays are used to implement on/off and polarity rever- 
sal functions for the two motors. Size 4 AWG welding cable is used for all high-current wiring outside the control module; size 6 AWG wire is used inside the module.

\section{FIELD TEST}

In late-July 1996, the drill was transported by Helio Courier aircraft from the Arctic Institute of North America Kluane Lake Research Station to Eclipse Dome, a small ice rise at $60^{\circ} 51^{\prime} \mathrm{N}, 139^{\circ} 47^{\prime} \mathrm{W}$. The drill site is at $2950 \mathrm{~m}$ a.s.l. and has a mean annual accumulation rate of approximately $1.5 \mathrm{~m}$ w.e. year ${ }^{-1}$ (Holdsworth, 1985).

Though the drill can be operated comfortably by two people, the field party consisted of three people. It took one person 5 hours to assemble the drill and dig the drill trench. Drilling was accomplished in the open with no shelter. Because solar heating caused melting on the drill, most drilling was done at night, with the drill stored at depth during the day to keep it cold. A $2.2 \mathrm{~kW}$ Honda generator charging a $24 \mathrm{~V}, 32 \mathrm{~A}$ h battery bank was used for the field test.

\section{Core recovery}

Total depth drilled was $161.6 \mathrm{~m}$ below surface over 5.5 days. Figure 3 shows the cumulative drill advance and core recovery. Aside from approximately $60 \mathrm{~cm}$ of core lost in the upper $2 \mathrm{~m}$ due to soft snowpack, core recovery is believed to be virtually complete (calculated value is $99.7 \%$ ). Core quality from $2 \mathrm{~m}$ to approximately $136 \mathrm{~m}$ was very good to excellent; below this depth, core quality varied from fair to good. The entire $161 \mathrm{~m}$ core was cut in half lengthwise in the field and one half of the core has been returned to the University of New Hampshire for analysis; the remainder of the core is archived on site but will be retrieved in 1997 or 1998.

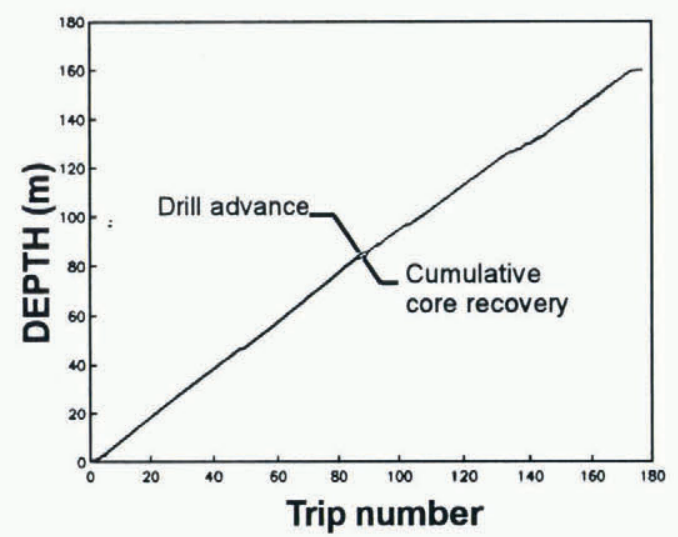

Fig. 3. Drill advance and cumulative core recovery vs trip number for the July 1996 field test.

Figure 4 shows the core length retrieved vs drill depth. A total of ten trips retrieved no core (recorded as $0 \mathrm{~cm}$ ). The average advance per trip, including trips when there was no advance or core recovery, was $92 \mathrm{~cm}$; typical advance per trip was $100 \mathrm{~cm}$.

\section{Power consumption and performance}

When idling, the drill motor consumes $120 \mathrm{~W}$; when drilling at $1.1 \mathrm{~cm} \mathrm{~s}^{-1}$, the motor draws $180 \mathrm{~W}$ and the switching power supply draws $250 \mathrm{~W}$. Approximately $20 \mathrm{~W}$ are lost as heat in

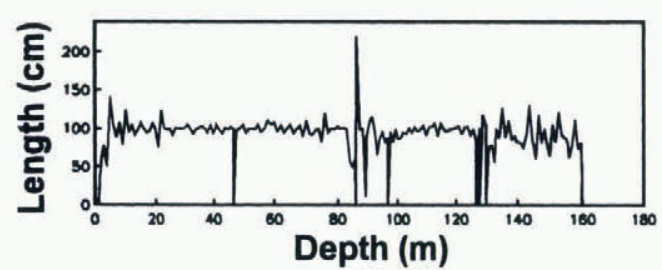

Fig. 4. Core length vs drill depth for the July 1996 field test.

the cable. The winch motor consumes $690 \mathrm{~W}$ at a top speed of $42 \mathrm{~cm} \mathrm{~s}^{-1}$ during ascent; the power consumption drops to $160 \mathrm{~W}$ at $60 \mathrm{~cm} \mathrm{~s}^{-1}$ during descent.

\section{Trip time}

The total time required for a complete trip (lowering drill, drilling, raising core, core removal/handling and resetting the drill) varies, of course, with depth. At a depth of $140 \mathrm{~m}$, trip time was $16 \mathrm{~min}$; at a depth of $160 \mathrm{~m}$, trip time was $18 \mathrm{~min}$

\section{MOUNT EVEREST DRILL SEASON}

In May 1997, a drill camp on the north side of Mount Everest was established by Wake and others (personal communication from C. P. Wake). After vehicular transport to Everest base camp, Tibet, at $5200 \mathrm{~m}$ a.s.l. the drill system was carried $10 \mathrm{~km}$ by yaks and a further $5 \mathrm{~km}$ by porters to the drill site on Far East Rongbuk Glacier ( 6500 m a.s.l.; $28^{\circ} 06^{\prime} \mathrm{N}, 86^{\circ} 58^{\prime} \mathrm{E}$ ). Unforeseen delays resulted in a shortage of time, so drilling was limited to $42 \mathrm{~m}$ of core. The drill performed flawlessly.

\section{CONGLUSIONS}

The ECLIPSE drill system meets our requirements for high-altitude fieldwork. The drill can be dismantled and carried by hand. When dismantled, the mass of the heaviest component (winch drum with $250 \mathrm{~m}$ of cable) is $33 \mathrm{~kg}$ and the length of the longest component (outer barrel) is $2.82 \mathrm{~m}$. The entire drill (including spare parts and toolkit) breaks down into eight or nine porter loads. The total mass of the drill is $195 \mathrm{~kg}$.

A $101 \mathrm{~mm}$ version of the ECLIPSE drill has been designed but not yet built.

\section{ACKNOWLEDGEMENTS}

The strong support of D. A. Fisher and R. M. Koerner of the GSC has been invaluable in the development of this drill; drawings for the HILDA drill were licensed from the GSC and the National Research Council of Canada. The authors wish to acknowledge the field assistance of S. Williams, whose participation was made possible by a grant from the Northern Research Institute, Yukon. Our pilot, A. Williams, must receive thanks for his considerable efforts. Heritage Canada, Kluane National Park and Heritage Branch, Yukon Government, were kind enough to grant research permits for the field test. U.S. National Science Foundation grant ATM-9417818 supported the development, construction and testing of the ECLIPSE drill. 


\section{REFERENCES}

Gundestrup, N. S., S. B. Hansen and S. J. Johnsen. 1989. Refinements of the UCPH shallow drill. In Rado, C. and D. Beaudoing, eds. Ice core drilling. Proceedings of the Third International Workshop on Ice Drilling Technology, Grenoble-France, 10-14 October 1988. Grenoble, Centre National de la Recherche Scientifique. Laboratoire de Glaciologie et Géophysique de l'Environnement, 6-13.

Holdsworth, G. and E. Peake. 1985. Acid content of snow from a mid-troposphere sampling site on Mount Logan, Yukon Territory, Canada. Ann.
Glaciol., 7, 153-160.

Johnsen, S. J., W. Dansgaard, N. Gundestrup, S. B. Hansen, J. O. Nielsen and N. Reeh. 1980. A fast light-weight core drill. f. Glaciol., 25(91), 169-174.

Rand, J. H. 1976. The USA CRREL shallow drill. In Splettstoesser, J. F., ed. Ice-core drilling. Lincoln, NB, University of Nebraska Press, 133-137.

Rech, N. 1984. Antitorque leaf springs: a design guide for ice-drill antitorque leaf springs. CRREL Spec. Rep. 84-34, 69-72.

Rufli, H., B. Stauffer and H. Oeschger. 1976. Lightweight 50-meter core drill for firn and ice. In Splettstoesser, J. F., ed. Ice-core drilling. Lincoln, NB, University of Nebraska Press, 139-153.

MS received 17 February 1997 and accepted in revised form 30 June 1997 